\title{
Recursos Educacionais Abertos - Padrões de Licenças para Arquivos Abertos
}

\author{
Edilaine Vagula? \\ Edwylson de Lima Marinheiro² \\ Mari Clair Moro Nascimento
}

\begin{abstract}
Resumo: $\bigcirc$ artigo tem como objetivo refletir sobre as contribuições dos Recursos Educacionais Abertos para a construção do conhecimento escolar, analisando as licenças disponíveis no Creative Commons. Trata-se de uma pesquisa bibliográfica, no contexto da produção do REA, promovendo o debate sobre a questão dos direitos autorais representados por licenças. Conclui-se que a licença, quando aberta, permite que o REA seja adaptado, promovendo autonomia, por meio de uma cultura flexível de colaboração, possibilitando inovações no campo educacional. O professor que trabalha com metodologia participativa e dialógica e faz uso do REA em sala de aula, promove situações desafiadoras que mobilizam o aluno para a construção do conhecimento, aliando ensino à pesquisa.

Palavras-chave: Recursos Educacionais Abertos. Creative Commons. Educação básica.
\end{abstract}

\section{Open Educational Resources - License Patterns for Open Files}

\begin{abstract}
The article aims to reflect on the contributions of the Open Educational Resources in the process of building school knowledge, thru analyzing the licenses available at Creative Commons. It is a bibliographical research, in the context of the production of OER, promoting the debate on the issue of copyright represented by such licenses. It can be concluded that the license, when open, allows the OER to be adapted, promoting autonomy, through a flexible culture of collaboration, enabling innovations in the educational field. The teacher who works with participatory and dialogic methodology and makes use of OER in the classroom, promotes challenging situations that mobilize the student to build knowledge, combining teaching with research.
\end{abstract}

Keywords: Open Educational Resources. Creative Commons. Basic education.

'Possui graduação em Pedagogia pela Universidade Estadual de Londrina (1988), Mestrado em Educação pela UEL (2004) e Doutorado em Educação pela Pontifícia Universidade Católica do Paraná (2014). Atualmente é professora do Departamento de Educação, da Universidade Estadual de Londrina.

${ }^{2}$ Mestre em Educação (UEL); Licenciado em Pedagogia (2013) pela Universidade Estadual de Londrina (UEL); Licenciado em Geografia (2005) pela Universidade Estadual de Londrina (2005); Atualmente exerce a função de Gerente de Gestão Financeira da Secretaria Municipal de Educação de Londrina;

3Doutora Doutora em Educação pela Universidade Estadual Paulista Júlio de Mesquita Filho-Câmpus de Marilia (UNESP) (2018), Mestrado em Educação pela Universidade Estadual de Londrina (2012), Atualmente é Professora da Educação a Distância na Universidade Norte do Paraná. 


\title{
Recursos Educativos Abiertos - Estándares de Licencias para Archivos Abiertos
}

\begin{abstract}
Resumen: El artículo tiene como objetivo reflexionar sobre las contribuciones de los Recursos Educativos Abiertos para la construcción del conocimiento escolar, analizando las licencias disponibles en el Creative Commons. Se trata de una investigación bibliográfica, en el contexto de la producción del REA, promoviendo el debate sobre la cuestión de los derechos de autor representados por licencias. Se concluye que la licencia, cuando abierta, permite que el REA sea adaptado, promoviendo autonomía, por medio de una cultura flexible de colaboración, posibilitando innovaciones en el campo educativo. El profesor que trabaja con metodología participativa y dialógica y hace uso del REA en el aula, promueve situaciones desafiantes que movilizan al alumno para la construcción del conocimiento, aliando enseñanza a la investigación. Palabras clave: Recursos Educativos Abiertos. Creative Commons. Educación básica.
\end{abstract}

\section{Introdução}

O artigo tem como objetivo refletir sobre as contribuições do REA - Recursos Educacionais Abertos para a construção do conhecimento escolar, analisando as licenças disponíveis no Creative Commons. O termo REA - Recurso Educacional Aberto surgiu a partir do Forumonthe Impact of Open Course ware for Higher Education in Developing Countries (Fórum sobre o Impacto do Curso Aberto para a Educação Superior em Países em Desenvolvimento) organizado pela UNESCO e financiado pela Fundação Hewlett. No ano de 2005, a UNESCO criou a OER Community wiki para socializar trabalhos de forma colaborativa e Open Course Ware Consortium, uma comunidade mundial composta por instituições de educação e organizações associadas que facilitam o acesso e a propagação dos REAs. O movimento, contudo, teve seus primórdios em 1999, dentro do MIT - Massachusetts Institute of Technology - sugerindo a possibilidade de a internet subsidiar a produção do conhecimento, tomando por princípio o conhecimento como bem público (PEÑA; et al., 2012).

O REA pode ser composto por vídeos, imagens, livros, artigos, materiais de cursos, módulos de conteúdo, arquivos de texto, revistas, músicas, podcasts, livros didáticos, videoclipes e outros tipos de materiais, podendo contemplar orientações ao professor. Os REAs são disponibilizados gratuitamente e representam uma nova possibilidade de compartilhar conhecimento de forma colaborativa, ampliando o acesso a experiências e saberes. Assim, podem ser definidos como recursos pedagógicos digitalizados, constituídos por documentos ou mídias, que, por serem de domínio público e terem licença aberta, como por exemplo, a Creative commons, podem ser usados, reutilizados e reaproveitados, oferecendo a possibilidade de uso como recurso de ensino ou material de pesquisa.

O movimento Acesso Aberto tem sido disseminado no Brasil por instituições governamentais e não governamentais, contribuindo para a disponibilização de material científico e didático em repositórios que são autossustentáveis, em relação ao armazenamento da produção científica

Trata-se de um estudo de abordagem qualitativa, assim é preciso considerar que o tipo de pesquisa que mais se ajustou aos objetivos estudados foi à bibliográfica. Em nosso caso, para encontrarmos respostas que pudessem nos levar a compreender as 
contribuições das licenças Creative Commons para a disseminação dos REAs e suas possibilidades de acesso à cultura.

\section{REA e Educação}

No contexto da produção do REA e levando em consideração a sua utilização e possibilidade de acesso a cultura, é necessário trazer para o debate a questão dos direitos autorais representados por licenças, a fim de que se assegure a propriedade intelectual. Algumas propostas defendem a liberdade total para utilização e manipulação dos produtos abertos, como é o caso da Open Publication License (OPL), GNU General Public License (GPL) e GNU Free Documentation License (GFDL).

A literatura voltada para a produção do REA afirma que, ao selecionar uma licença e publicar sua produção, o autor passa a ter direitos autorais. Desta forma, os detentores de copyright - todos os direitos reservados passam ao escolher um padrão de licença em uma perspectiva oposta, ou seja, o copyleft, podendo ser total ou mais restritiva, em relação à propriedade intelectual. Quando publicamos sem deixar clara a licença, a lei interpreta que a obra é copyright. Neste caso, todos os direitos estão reservados ao autor ou a quem for concedida a licença, como uma editora, por exemplo. A lei brasileira é bem restritiva neste aspecto e, assim sendo, é importante esclarecer o que o autor libera da sua produção.

Na Educação Básica, utilizam-se os livros didáticos escolhidos pelos professores e adquiridos via governo federal, mas, por apresentarem direitos autorais, o professor não tem a possibilidade de remixar, destituindo-o do direito da possibilidade de autoria. O interessante, então, seria que estes professores fossem incentivados pela instituição ou mesmo pela mantenedora a produzirem conhecimento.

Como proposta de educação aberta, o governo do Estado do Paraná criou o Projeto FoIhas (2004) e o Livro Didático Público. Quanto ao Projeto, que é uma proposta de formação continuada, encontramos em documentos oficiais como objetivos, a produção e o compartilhamento com a intenção de tornar mais autônomos os profissionais da educação. O livro didático público é um material organizado por professores da rede estadual para utilização no ensino médio.

Analisando as possibilidades de disponibilização de licenças para conteúdos abertos, Dutra e Tarouco (2007) afirmam que, em relação aos direitos autorais, as licenças foram criadas com base na FLOSS. (Free Libre and Open Source Software). Trata-se de um movimento que difunde o software livre, como por exemplo, o Linux e o Mozila. Para Santos (2012), o termo Conteúdo Aberto (Open Content) foi criado a partir do movimento de código aberto - FLOSS (FREE/Libre Open Source Software) para a construção de materiais digitais para a educação, nos quais o autor pudesse agir com autonomia para adaptar e redistribuir seu software. FLOSS corresponde a um software livre para ser usado para qualquer finalidade, sendo possível aprofundar conhecimento, adaptar, modificar e redistribuir, geralmente é distribuído com a colaboração de voluntários, como parte de um projeto de desenvolvimento de software open-source.

Partindo da experiência do FLOSS, houve o incentivo a países em desenvolvimento para a criação de recursos educacionais abertos. No ano de 2002, o grupo de pesquisa GSyC/ LibreSoft, da Universidade Rey Juan Carlos pesquisou e colaborou com o Freee Libre Open Source Software (FLOSS)com a intenção de avaliar o desenvolvimento da comunidade REA, contribuindo com o código aberto e projetos de software livre. 
O termo software livre não é recente, surgiu em 1985 na fundação do projeto GNU em colaboração para criar um sistema livre. Assim, o Projeto GNU é um software livre, com o objetivo de construir, de maneira colaborativa, um software livre com o qual fosse possível criar, distribuir, compartilhar, copiar ou modificar. Disponibilizados de forma gratuita, os sistemas operacionais de código aberto, como o GNU/Linux, são muito utilizados atualmente.

Dutra e Tarouco (2007) apresentam as principais licenças, entre elas, destaca-se a Open Content License \& Open Publication License. Sustentada em princípios da FLOSS, apresenta uma variedade de conteúdos, "expressa em três graus de liberdade: o direito de fazer cópias, o direito de redistribuir o conteúdo e o direito de modificar o conteúdo". A licença é totalmente aberta e prevê "que trabalhos podem ser reproduzidos e distribuídos na sua totalidade ou em partes em qualquer tipo de mídia, onde qualquer publicação em formato de livro requer a correta citação do autor ou editor original" (OPL, 2007; LIANG, 2005, apud Dutra e Tarouco, 2007, p. 3). Esta licença não diz respeito ao modelo copyleft, por não ser uma licença de documentação livre.

Outra licença abordada pelos autores é a GNU Free Documentation License que, por ser de documentação aberta, assenta-se no modelo copyleft. Assim, "pode ser utilizada para a documentação de manuais e também para outros tipos de trabalhos como livros dicionários, não se restringindo somente para trabalhos textuais" (GNU, 2007, apud DUTRA TAROUCO, 2007, p. 3).

De ampla aceitação e "Inspirada no movimento FLOSS, a Creative Commons se baseia no conceito de que é preciso criar e disponibilizar uma grande quantidade de informações e conteúdos, com vistas a assegurar a criatividade de forma sustentada" (DUTRA TAROUCO, 2007, 4).

No exercício cotidiano de suas tarefas, o professor pode disponibilizar suas produções e todo o tipo de material que possa ser utilizado com os alunos com a possibilidade de adaptação a diferentes contextos. Práticas educacionais abertas

[...] direcionam para uma postura crítica diante do conhecimento, principalmente diante da expansão do conceito de autoria reconhecem que o recurso didático deve ser manipulável e adaptável aos contextos de aprendizado; e promovem a flexibilização das configurações de ensino e aprendizagem. (GESSER, 2007 apud AMIEL, 2012, p.27).

O Projeto Creative Commons, criado por Lawrence Lessig, surgiu em 2001, como suporte para publicação de REA, disponibiliza licenças para uso e compartilhamento em repositórios, como, por exemplo, Wikimedia Commons, o Flickr Commons, e, por ser de fácil compreensão, tem sido a mais utilizada. Em 2012, surge o primeiro grupo de licenças (PEÑA, 2012). A licença, quando aberta, permite que o REA seja adaptado, promovendo autonomia, através de uma cultura flexível de colaboração, possibilitando inovações no campo educacional.

Quando se tem acesso a um determinado REA e se tem a intenção de reutilizá-lo, no sentido de transformação, torna-se necessário observar o tipo de licença, tendo o cuidado para atribuir créditos ao autor. Silveira (2012, p. 112), ao desenvolver um estudo dedicado ao formato aberto, descreve: 
chados e proprietários. Isso quer dizer que o código que contém as instruções para o computador salvar e recuperar as informações não é acessível a todos, sendo patenteado ou licenciado em copyright pelo seu desenvolvedor. Quando o formato tem sua codificação aberta e não está submetido a bloqueios legais de uso é chamado de formato aberto. o doc da Microsoft, por exemplo, é um formato fechado e o odt é um formato aberto.

A Creative Commons, surgido na internet, trata-se de uma ONG que se difundiu por diversos países e aqui no Brasil é mantida pela Fundação Getúlio Vargas. Seis licenças que, combinadas, apresentam a comunicação dos direitos por meio de símbolos, de fácil compreensão.

\footnotetext{
o creative Commons é uma organização não governamental que tem como foco a elaboração e manutenção de licenças livres que auxiliam na cultura de criação e compartilhamento, que tomou força com a expansão mundial da Internet. Hoje as licenças estão em sua terceira versão e foram adotadas e adaptadas por mais de cinquenta e cinco países, inclusive pelo Brasil. (EDUCAÇÃO ABERTA, 2012).
}

Conforme a atribuição da licença que se deseja, foram desenvolvidos vários tipos de licença, para compartilhar o REA e informar sobre direitos e também o seu uso. Tais licenças são apresentadas no quadro 1

\section{QUADRO 1 - Licenças}

\section{Atribuição}

CC BY

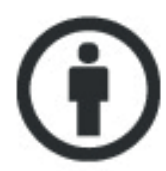

BY

Esta licença permite que outros distribuam,remixem, adaptem e criem a partir do seu trabalho, mesmo para fins comerciais, desde que the atribuam o devido crédito pela criação original. É a licença mais flexível de todas as licenças disponíveis. É recomendada para maximizar a disseminação e uso dos materiais licenciados.

Atribuição

CC BY-AS

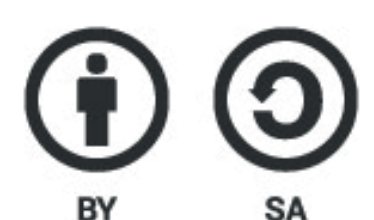

Esta licença permite que outros distribuam,remixem, adaptem ou criem obras derivadas, mesmo que para uso com fins comerciais, contanto que seja dado crédito pela criação original. esta é a licença menos restritiva de todas as oferecidas, em termos de quais usos outras pessoas podem fazer de sua obra. Atribuição - compartilhamento pela mesma licença (by-sa)

Atribuição-Sem

Derivações

CC BY-ND

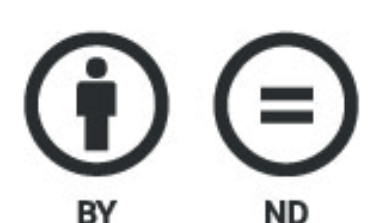

Esta licença permite a redistribuição, comercial e não comercial, desde que o trabalho seja distribuido inalterado e no seu todo, com crédito atribuido a você. 
Atribuição-Não Comercial CC BY-NC

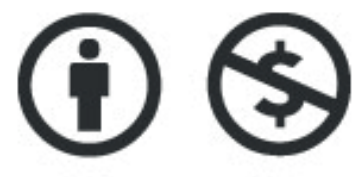

BY

NC

Esta licença permite que outros remixem, adaptem e criem a partir do seu trabalho para fins não comerciais, e embora os novos trabalhos tenham de lhe atribuir o devido crédito e não possam ser usados para fins comerciais, os usuários não têm de licenciar esses trabalhos derivados sob os mesmos termos.

\section{Atribuição-Não Comercial}

CC BY-NC-AS

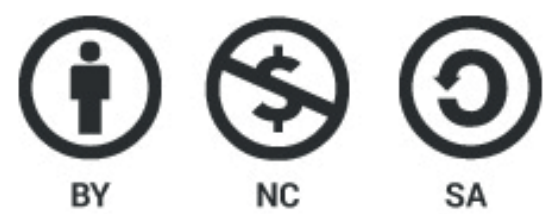

Esta licença permite que outros remixem, adaptem e criem a partir do seu trabalho para fins não comerciais, desde que atribuam a você o devido crédito e que licenciem as novas criações sob termos idênticos.

Atribuição-Sem

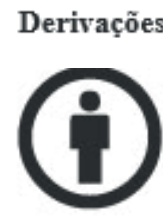

BY

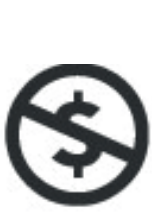

NC
Sem

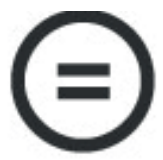

ND

Derivados

Esta é a mais restritiva das nossas seis licenças principais, só permitindo que outros façam download dos seus trabalhos e os compartilhem desde que atribuam crédito a você, mas sem que possam alterá-los de nenhuma forma ou utilizá-los para fins comerciais.

\section{Fonte: CreativeCommons}

Estas diversas possibilidades de licenciamento são definidas no formato doc, nem todos os usuários conseguem abrir docx, pois nem sempre têm um determinado software. O formato livre deve possibilitar a abertura de qualquer arquivo independentemente de seu formato ou hardware. Os formatos abertos apresentam códigos compartilhados. O direito de ser autor nunca é cedido, assim, o autor deve ser sempre citado, mas deve facilitar o reuso.

Remixar é garimpar em diversos sites, unir produções, organizar novos materiais e realizar novas publicações tendo o cuidado para citar os autores que foram utilizados. Pela Creative Commons, é possível traduzir os REAs para outras línguas, selecionar REAs de grande relevância', ampliar, realizar adaptações que atendam a diferentes realidades e reestruturar textos de livros, entre outros.

Quando elaboramos um REA, podemos selecionar as licenças, CC - Creative Commons lembrando que todas as licenças CC exigem que seja atribuído crédito de autoria para o autor original. O uso não comercial indica que são permitidas cópias para exibição e distribuição entretanto sem fins comerciais. Sobre a partilha dos mesmos termos, somente podem ser copiadas e distribuídas as cópias originais das obras.

Muitos que fazem uso do REA e o modificam encontram licenças com proibição de obras derivadas que necessitam de permissão para alteração. As CC são licenças que apresentam conteúdo aberto. O quadro abaixo caracteriza os principais projetos internacionais voltados para o REA 
Quadro 2 - Projetos Internacionais com foco no REA, comunidades abertas de pesquisa, tecnologias e práticas educacionais

\begin{tabular}{|c|c|c|}
\hline Projeto & Descrição & Audiência \\
\hline OPENLEARN & $\begin{array}{l}\text { repositório e área experimental } \\
\text { para reutilização, remixagem e } \\
\text { compartilhamento de rea }\end{array}$ & $\begin{array}{l}\text { aberta para qualquer usuário } \\
\text { interessado em materiais de } \\
\text { cursos do ensino. }\end{array}$ \\
\hline COLEARN & $\begin{array}{l}\text { comunidade online de pesquisa } \\
\text { aberta. parte do projeto de } \\
\text { pesquisa "open } \\
\text { sensemakingcommunititeis" - } \\
\text { iniciativa do knowledge media } \\
\text { institute ou -uk. }\end{array}$ & $\begin{array}{l}\text { aberta para qualquer interessado } \\
\text { em compartilhar teorias, práticas, } \\
\text { pesquisas, reas, projetos e } \\
\text { publicações colaborativas. }\end{array}$ \\
\hline ICOPER & $\begin{array}{l}\text { rede de melhores práticas para } \\
\text { compartilhamento de recursos } \\
\text { educacionais interoperáveis no } \\
\text { ensino superior com foco no } \\
\text { desenvolvimento } \\
\text { competências. }\end{array}$ & $\begin{array}{l}\text { aberta para quaisquer instituições } \\
\text { de ensino superior, provedores de } \\
\text { tecnologias e organizações } \\
\text { voltadas para desenvolvimento } \\
\text { de padrões e especificações }\end{array}$ \\
\hline OLCOS & $\begin{array}{l}\text { grupo de pesquisa direcionado } \\
\text { para investigar e compreender } \\
\text { como REA pode contribuir como } \\
\text { novos modos de aprender num } \\
\text { mundo mais aberto. }\end{array}$ & $\begin{array}{l}\text { aberta para qualquer comunidade } \\
\text { de pesquisa de rea, } \\
\text { desenvolvedores, tecnologistas e } \\
\text { consultores. }\end{array}$ \\
\hline OPENSCOUT & $\begin{array}{l}\text { integração de conteúdos, práticas } \\
\text { e tecnologias para gestão de } \\
\text { conteúdos educacionais na área } \\
\text { de administração e negócios. }\end{array}$ & $\begin{array}{l}\text { integração de conteúdos, práticas } \\
\text { e tecnologias para gestão de } \\
\text { conteúdos educacionais na área } \\
\text { de administração e negócios. }\end{array}$ \\
\hline
\end{tabular}

Fonte: OKADA (2017, p.8)

Entre os projetos apresentados no quadro, o OpenLearn, da Open University - Reino Unido corresponde ao de maior abrangência. Utiliza-se do moodle e oferta cursos online, permitindo o acesso a diversos conteúdos, sendo possível, também, criar um perfil e fazer download do mesmo. Apresenta outras possibilidades, como fórum, permitindo o acesso a comunidades virtuais de aprendizagem. O repositório do REA é inovador e o usuário pode publicar seu conteúdo na plataforma (SANTOS, 2012).

Os repositórios digitais, por apresentarem acesso livre, permitem democratizar, gratuitamente, a produção científica por meio da internet. Este movimento foi apoiado pelo Instituto Brasileiro de Informação em Ciência e Tecnologia (Ibict) com o objetivo de subsidiar a implantação do acesso livre e amplo. (RODRIGUES, 2012)

\footnotetext{
Mediante o conceito de filosofia aberta, conhecida também como Open Acess, qualquer indivíduo, independente da sua localização, pode acessar materiais acadêmicos ou científicos, sem nenhum tipo de restrição ou custo. Assim, compreende-se que os repositórios digitais são constituídos por um sistema de informação que permite armazenar, organizar e compartilhar diferentes tipos de materiais, a fim de proporciona um acesso transparente e democrático (RODRIGUES et al., 2012, p. 112-113)
} 
o conhecimento e o desenvolvimento de políticas públicas.

Em 2007, iniciou-se o trabalho com o movimento Open Access para o crescente campo da OER. Com apoio da Fundação Shuttleworth, foi lançada, em 2008, a Declaração da Cidade do Cabo - Educação Aberta, promovendo a discussão sobre o acesso público a financiamentos e materiais educacionais. Sabemos que, com a referida Declaração, surgem novas possibilidades para o trabalho com o REA, desenvolvido de forma colaborativa, a partir de licenças de conteúdo aberto, e do surgimento de políticas públicas.

No ano de 2011, a comunidade REA divulgou o projeto de lei n. 1513/2011, do deputado federal Paulo Teixeira, do Estado de São Paulo, que, após consideráveis discussões e alterações, obteve sua aprovação em dezembro e "dispõe sobre a contratação e licenciamento de obras intelectuais subvencionadas pelos entes do Poder Público e pelos entes do direito privado sob controle acionário de entes da administração pública". Tal projeto tinha a finalidade de apoiar e ampliar recursos das prefeituras, pela aquisição de material didático-pedagógico e valorização do magistério público.

Todo o movimento de Educação Aberta tem como propulsor a Declaração sobre Educação Aberta da Cidade do Cabo em 2007, baseada nas seguintes linhas de atuação:

\footnotetext{
Política de educação aberta: governos, escolas, faculdades e universidades devem fornecer os recursos educacionais pagos com o dinheiro dos contribuintes como REA;

Licenças de conteúdo aberto: os REA devem poder ser livremente partilhados através de licenças abertas, as quais facilitam o uso, a revisão, as melhorias e o compartilhamento;

Produção colaborativa: educadores e estudantes podem participar criando, usando adaptando e melhorando os REA (ROSSINI; GONZALES, 2012, p. 42).
}

No Brasil, o debate político sobre REA, para a disseminação e utilização de recursos educacionais, tem como pressupostos o acesso a recursos educacionais, a produção colaborativa de conhecimento e a economia na produção de materiais educacionais, pois a educação é um direito público subjetivo. Preconiza, ainda, os benefícios do REA em relação às estratégias de aprendizagem, assim como o respeito às regionalidades e a discussão dos REAs na formação continuada dos professores. (ROSSINI; GONZALES, 2012). Estes autores também destacam o Plano Nacional de Educação (PNE), que revela a preocupação com a qualidade da educação brasileira e a ampliação das médias nacionais para o Índice de Desenvolvimento da Educação Básica (Ideb). Para Rossini e Gonzales (2012, p.58)

\begin{abstract}
Selecionar, certificar e divulgar tecnologias educacionais para educação infantil, o ensino fundamental e ensino médio, assegurada a diversidade de métodos e propostas pedagógicas, com preferência para software livre e recursos educacionais abertos bem como acompanhamento dos resultados do sistema de ensino que forem aplicadas; Implementar o desenvolvimento de tecnologias educacionais, e de inovação das práticas pedagógicas nos sistemas de ensino, inclusive a utilização de recursos educacionais abertos, que assegurem a melhoria do fluxo escolar e a aprendizagem de alunos.
\end{abstract}

O professor que trabalha com metodologia participativa e dialógica, é possível fazer escoIhas por meio de situações desafiadoras que mobilizem o aluno para a construção do conhecimento por meio do REA, aliando ensino à pesquisa. 


\section{Considerações Finais}

O movimento REA cresceu consideravelmente nos últimos anos em estreita relação com a aprendizagem colaborativa e o acesso, por ser aberto, amplia as possibilidades de disseminar o conhecimento científico. Diante das inúmeras possibilidades do REA, é, portanto, mais que necessário o surgimento de políticas públicas nacionais e locais que privilegiem o seu uso e promovam a inovação e o acesso à educação, com o desenvolvimento de ações financiadas pelo poder público, que possam conferir-Ihes o apoio necessário. Acompanhamos, nos últimos tempos, a influência exercida pela Comunidade REA Brasil na efetivação de políticas públicas para incentivar a aquisição de REAs e software educacionais livres pelo governo e, como se pode constatar, já é possível perceber que as propostas têm sido contempladas por políticas públicas.

O uso frequente do REA em sala de aula pode levar professores e alunos a aprimorarem o material produzido, a fornecerem subsídio para a criação de novas formas de ensinar, a se mobilizarem diante do inusitado, a familiarizarem-se com as TIC, tornando-se parceiros. 0 avanço da tecnologia e sua inserção no contexto escolar desafia o professor a propor novas formas de comunicar e construir o conhecimento, estimulando processos de criação, intensificando a produção e propagação do conhecimento em rede.

\section{Referências}

AMIEL, R. Educação aberta: configurando ambientes, práticas e recursos Educacionais. In: SANTANA, B.; ROSSINI; C.; PRETTO, N. De L. (Org.). Recursos Educacionais Abertos: práticas colaborativas e políticas públicas Salvador: Edufba; São Paulo: Casa da Cultura Digital, 2012. Disponível em: <http://livrorea.net.br/livroREA-1edicao-mai2012.pdf>. Acesso em: 05 abr. 2012. p.17-33.

DUTRA, R. L. S.; TAROUCO, L. M. R. Recursos Educacionais Abertos (Open Educational Resources). 2007. Centro Interdisciplinar de Novas Tecnologias da Educação. Universidade Federal do Rio Grande do Sul. Disponível em: <http://www.cinted.ufrgs.br/ciclog/artigos/ 4fRenato.pdf>. Acesso em: 20 jul. 2013. 2007. p.1-8.

PEÑA, M.; et al. Recursos Educacionais Abertos: nova cultura de produção e socialização de saberes no ciberespaço. In: Okada, A. (Ed.) (2012) Open Educational Resources and Social Networks: Co-Learning and Professional Development. London: Scholio Educational Research \& Publishing. Disponívelem: <http://oer.kmi.open.ac.uk/wp-content/uploads/cap04_edutechi.pdf>. Acesso em 07 Out. 2013.

RODRIGUES, P. A. A. et al. Banco Internacional de Objetos Educacionais: Repositório Digital para o uso da Informática na Educação. 2012. Revista Brasileira de Informática na Educação, Vol. 20, n. 1, 2012. p. 117-120. Disponível em: <http://ceiesbc.educacao.ws/pub/index. php/rbie/article/view/1364/1798>. Acesso em: 04 jul 2013.

ROSSINI, C.; GONZALEZ, C. REA: o debate em políticas e as oportunidades para o mercado. In: SANTANA, B.; ROSSINI, C.; PRETTO, N. de L. Recursos Educacionais Abertos: práticas colaborativas políticas públicas. São Paulo: Casa da Cultura Digital. 2012, pp. 35-69. 
SANTOS, A. I. Educação aberta: histórico, práticas e o contexto dos recursos educacionais abertos. In SANTANA, B.; ROSSINI, C.; PRETTO, N. de L. Recursos Educacionais Abertos: práticas colaborativas políticas públicas. São Paulo: Casa da Cultura Digital. 2012.

SILVEIRA, S. R.; BARONE, D. A. C. Formação de grupos colaborativos em Cursos a Distância via WEB: um estudo de caso utilizando as técnicas de inteligência Artificial. In: Revista Brasileira de Informática na Educação. Vol. 14, n.2, Maio/Agosto, 2006. p.29-40

TAROUCO, L. M. R. ARCA: Ambiente de realidade virtual cooperativo de aprendizagem. In: Revista Brasileira de Informática na Educação. n. 6. Abr/2000. p. 34-35. 